\title{
Williamsia serinedens sp. nov., isolated from an oil-contaminated soil
}

Correspondence

A. F. Yassin

yassin@mibi03.meb.uni-bonn.de
A. F. Yassin, ${ }^{1}$ Chiu Chung Young, ${ }^{2}$ Wei-An Lai, ${ }^{2}$ H. Hupfer, ${ }^{3}$ A. B. Arun, ${ }^{2}$ Fo-Ting Shen, ${ }^{2}$ P. D. Rekha ${ }^{2}$ and Mann-Jing $\mathrm{Ho}^{2}$

\author{
${ }^{1}$ Institut für Medizinische Mikrobiologie und Immunologie der Universität Bonn, 53127 Bonn, \\ Germany \\ ${ }^{2}$ College of Agriculture and Natural Resources, Department of Soil \& Environmental Sciences, \\ National Chung Hsing University, Taichung 402, Taiwan, ROC \\ ${ }^{3}$ Kekulé-Institut für Organische Chemie und Biochemie der Universität Bonn, 53121 Bonn, \\ Germany
}

The taxonomic status of a bacterium designated strain IMMIB SR $-4^{\top}$ isolated from an oil-contaminated soil sample was characterized by using a polyphasic approach. Chemotaxonomic investigations revealed the presence of cell-wall chemotype IV, short-chain mycolic acids that co-migrated with those extracted from members of the genus Williamsia and that on pyrolysis GC produce $\mathrm{C}_{16 \text { : } 0}$ and $\mathrm{C}_{18: 0}$ fatty acids, and dihydrogenated menaquinone with nine isoprene units as the predominant menaquinone. The generic assignment was confirmed by 16S rRNA gene sequence analysis. Comparative analysis of the 16S rRNA gene sequence showed that strain IMMIB SR $-4^{\top}$ formed a distinct phyletic line within the genus Williamsia, displaying sequence similarities of 95.5-98.1\% with the type strains of recognized Williamsia species. Strain IMMIB $\mathrm{SR}-4^{\top}$ was distinguished from the type strains of recognized species of the genus Williamsia based on a set of phenotypic features. The genotypic and phenotypic data indicated that strain IMMIB $\mathrm{SR}-4^{\top}$ represents a novel species of the genus Williamsia, for which the name Williamsia serinedens sp. nov. is proposed. The type strain is IMMIB SR $-4^{\top}\left(=\mathrm{DSM} 45037^{\top}=\mathrm{CCUG}\right.$ $\left.53151^{\top}\right)$.
The genus Williamsia (Kämpfer et al., 1999) as currently defined is a member of the family Gordoniaceae (Stackebrandt et al., 1997) and accommodates actinomycetes with atypical cell morphology that are unable to grow at temperatures above $30^{\circ} \mathrm{C}$, and possesses mycolic acids with carbon chain length of $\mathrm{C}_{50: 0}-\mathrm{C}_{56: 0}$. At the time of writing, the genus Williamsia comprised four recognized species, Williamsia deligens (Yassin \& Hupfer, 2006) isolated from human blood, Williamsia muralis (Kämpfer et al., 1999 ) isolated from indoor building material of a children's day-care centre in Finland, Williamsia maris (Stach et al., 2004) isolated from deep sediments of the Sea of Japan and Williamsia marianensis (Pathom-Aree et al., 2006) isolated from a deep-sea sediment. These species form a distinct clade within the evolutionary radiation occupied by mycolic-acid-containing actinomycetes, i.e. by organisms classified in the suborder Corynebacterineae (Stackebrandt et al., 1997). In the present paper we describe an actinobacterial strain, designated IMMIB SR-4 ${ }^{\mathrm{T}}$, which was isolated from an oil-contaminated soil sample. Based on

The GenBank/EMBL/DDBJ accession number for the $16 \mathrm{~S}$ rRNA gene sequence of strain IMMIB SR-4 ${ }^{\top}$ is AM283464. phylogenetic and phenotypic evidence, it is proposed that this isolate should be classified as representing a novel species of the genus Williamsia.

Isolate IMMIB SR-4 ${ }^{\mathrm{T}}$ was isolated from a soil sample collected from an oil-contaminated site located in Chyai County, Taiwan. The organism was cultured on Columbia agar supplemented with $5 \%$ sheep blood and brain heart infusion (BHI) agar to determine its morphological characteristics. Air-dried smears were stained via Gram's method in order to determine the Gram reaction and cell morphology. Ziehl-Neelsen's method was used to determine acid-fastness. Growth temperatures were determined by incubating the organism at $22,28,30,37$ and $42^{\circ} \mathrm{C}$. The physiological properties of the strain were determined by using tests for hydrolysis of complex substrates as described by Gordon (1966, 1967) and Gordon \& Mihm (1957) as well as tests for carbon source utilization according to Yassin et al. (1995). The isomeric form of diaminopimelic acid was determined according to the method of Becker et al. (1964) and whole-cell sugars were identified by using the method of Lechevalier (1968). Lipids were extracted by using acid methanolysis and mycolic acids were detected with TLC as described by Minnikin et al. (1980); pyrolysis GC of the 
mycolate was performed according to Yassin et al. (1993a). Fatty acids were purified, identified and quantified by GC as described by Yassin (1988). Phospholipids were extracted, purified and identified as described by Yassin et al. (1993b). Menaquinones were extracted and purified according to Collins et al. (1977). Mass spectra of the menaquinones were recorded in positive-ion mode on a Q-TOF 2 mass spectrometer (Micromass) equipped with a nanospray source as described by Yassin \& Hupfer (2006).

Genomic DNA extraction, PCR-mediated amplification of the $16 \mathrm{~S}$ rRNA gene and purification of PCR products were carried out according to the procedures of Rainey et al. (1996). Purified PCR products were sequenced by using a Taq DyeDeoxy Terminator cycle sequencing kit (Applied Biosystems) as described in the manufacturer's protocol. An Applied Biosystems 310 DNA Genetic Analyzer was used for electrophoresis of the sequence reaction products. The $16 \mathrm{~S}$ rRNA gene sequences of recognized species of the genus Williamsia retrieved from GenBank were added to the ARB database (Ludwig et al., 2004) and were aligned by using the respective tool within the ARB package. The resulting alignment was corrected manually and evolutionary trees were inferred using maximum-parsimony (Kluge \& Farris, 1969), neighbour-joining (Saitou \& Nei, 1987) and maximum-likelihood (Felsenstein, 1981) methods. The evolutionary distance matrix was calculated using the correction of Jukes \& Cantor (1969). The topology of the resultant tree was evaluated by bootstrap analyses (Felsenstein, 1985) of the neighbour-joining data based on 1000 resamplings by using the ARB package.

The almost-complete 16S rRNA gene sequence of strain IMMIB SR $-4^{\mathrm{T}}$ was determined [1479 nt; $95.9 \%$ of the Escherichia coli sequence (Brosius et al., 1978)]. 16S rRNA gene sequence comparison clearly indicated that strain IMMIB SR $-4^{\mathrm{T}}$ was a member of the suborder Corynebacterineae (Stackebrandt et al., 1997), and the sequence contained all signature nucleotides expected for this suborder as well as those described recently (Yassin \& Hupfer, 2006) for the family Gordoniaceae. Furthermore, the new isolate contained the signature nucleotides at positions 293-304 (G-C) and 307 (C) shared with other members of the genus Williamsia. However, strain IMMIB SR-4 $4^{\mathrm{T}}$ differed from recognized Williamsia species in that it possessed $C-G$ rather than $\mathrm{G}-\mathrm{C}$ at positions 1007:1022. Therefore, the current pattern of signature nucleotides for members of the genus Williamsia may need to be updated as novel species are described.

The phylogenetic tree constructed (Fig. 1) shows the position of strain IMMIB SR $-4^{\mathrm{T}}$ within the radiation of representative phylogenetic groups of the suborder Corynebacterineae. It is evident from the tree that strain IMMIB SR $-4^{\mathrm{T}}$ not only falls within the phylogenetic radiation occupied by the genus Williamsia but forms a distinct phyletic line that is loosely associated (bootstrap value of $55 \%$ ) with the type strains of $W$. maris and $W$. deligens. Strain IMMIB SR $-4^{\mathrm{T}}$ showed $16 \mathrm{~S}$ rRNA gene sequence similarities of 97.0 and $98.1 \%$ to $W$. maris SJS0289/JS1 ${ }^{\mathrm{T}}$ and $W$. deligens IMMIB RIV-956 ${ }^{\mathrm{T}}$, respectively, and 95.5 and $95.6 \%$ to $W$. marianensis $\mathrm{MT}^{\mathrm{T}}$ and $W$. muralis MA140/96 ${ }^{\mathrm{T}}$, respectively. Therefore, the distinctiveness of strain IMMIB SR-4 $4^{\mathrm{T}}$ from $W$. maris, $W$. marianensis and $W$. muralis is underpinned by exhibiting $\geqslant 3 \%$ sequence divergence (Stackebrandt \& Goebel, 1994) from these three species. It is known that the type strains of $W$. marianensis and W. muralis share high 16S rRNA gene sequence similarity $(99.5 \%$ or 7 nt differences out of 1443 positions) but belong to genomic species with a mean DNADNA relatedness value of $11 \%$ (Pathom-Aree et al., 2006). It is therefore evident that the high 16S rRNA gene sequence similarity found between strain IMMIB SR- $4^{\mathrm{T}}$ and the type strain of $W$. deligens $(98.1 \%$, corresponding to $30 \mathrm{nt}$ differences) indicates that the test strain represents a distinct taxonomic entity within the genus Williamsia. It is also clear from Table 1 that strain IMMIB SR $-4^{\mathrm{T}}$ can be distinguished readily from the type strain of $W$. deligens based on a set of biochemical properties.

Chemotaxonomically, strain IMMIB SR $-4^{\mathrm{T}}$ possessed chemical markers that supported its assignment to the genus Williamsia. The cell wall contained meso-diaminopimelic acid as well as arabinose and galactose (i.e. wall chemotype IV sensu Lechevalier \& Lechevalier, 1970). Onedimensional TLC of the whole-cell acid methanolysate of the

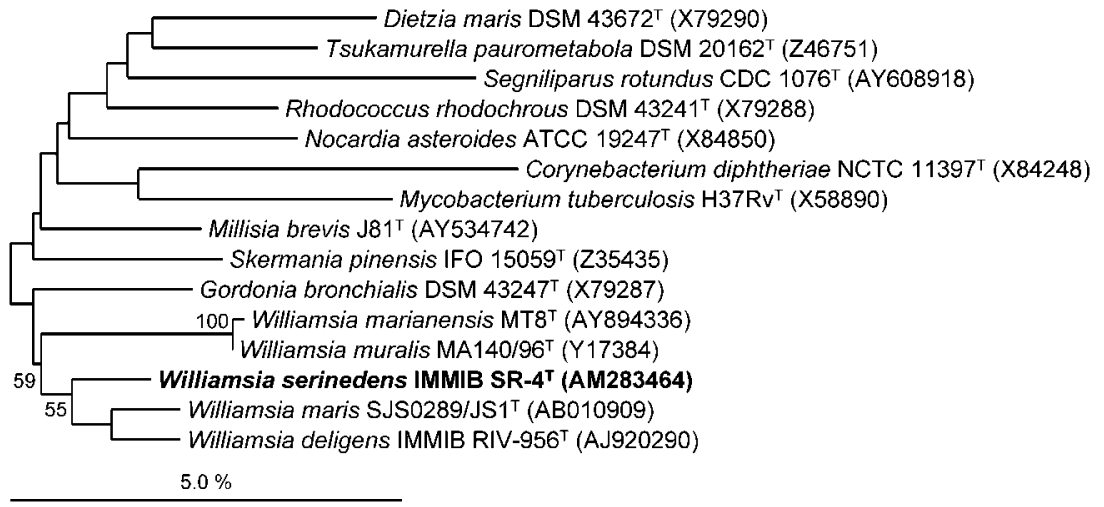

Fig. 1. Neighbour-joining tree showing the position of strain IMMIB SR-4 ${ }^{\top}$ within the radiation of mycolic-acid-containing taxa. The tree was based on a comparison of 16S rRNA gene sequences that were at least $90 \%$ complete (with regard to the $E$. coli sequence). Bootstrap values of $>50 \%$ (based on 1000 resamplings) are indicated at nodes. Bar, $5.0 \%$ sequence divergence. 
organism revealed the presence of two lipid spots on the chromatogram. The lower spot corresponded to mycolic acids as identified by its $R_{\mathrm{f}}$ value (0.55) and the higher spot corresponded to non-hydroxylated fatty acids. Pyrolysis GC of the purified mycolic acid methyl esters from strain IMMIB SR $-4^{\mathrm{T}}$ released fatty acid methyl esters of $\mathrm{C}_{16: 0}$ ( $55.0 \%$ of the total cleavage products) and $\mathrm{C}_{18: 0}(45.0 \%)$ as pyrolysis cleavage products. GC analyses of the nonhydroxylated fatty acid methyl esters revealed the presence of tetradecanoate ( $1.7 \%$ of the total fatty acids), pentadecanoate $(0.15 \%)$, cis-hexadecenoate $(0.35 \%)$, hexadecanoate $(15.6 \%)$, 10-methyl hexadecanoate $(0.52 \%)$, heptadecanoate $(0.16 \%)$, octadecenoate $(4.9 \%)$, octadecanoate $(7.4 \%)$, tuberculostearic acid (10-methyl octadecanoate; $17.1 \%)$, eicosenoate $(1.2 \%)$, eicosanoate $(0.57 \%)$, docosanoate $(15.8 \%)$, tetracosenoate $(1.3 \%)$ and tetracosanoate $(34.3 \%)$ as the major cellular fatty acid methyl esters. Polar lipid analysis showed that the organism contained phosphatidylethanolamine, phosphatidylinositol, phosphatidylglycerol and diphosphatidylglycerol as characteristic phospholipids (i.e. phospholipid type PII sensu Lechevalier et al., 1977). Mass spectral analysis of the main respiratory quinone components from strain IMMIB SR $-4^{\mathrm{T}}$ revealed a strong peak at $m / z 809.5$ attributable to $[\mathrm{M}+\mathrm{Na}]^{+}$in the high-mass region. This corresponds to a dihydrogenated menaquinone with nine isoprene units, MK-9 $\left(\mathrm{H}_{2}\right)$. The second band revealed a strong peak at $\mathrm{m} / \mathrm{z} 741.58$ attributable to $[\mathrm{M}+\mathrm{Na}]^{+}$in the high-mass region. This corresponds to a dihydrogenated menaquinone with eight isoprene units, MK-8 $\left(\mathrm{H}_{2}\right)$.

Strain IMMIB SR $-4^{\mathrm{T}}$ was examined for a range of phenotypic markers. The organism showed morphological properties consistent with its assignment to the genus Williamsia. It was aerobic, and built smooth, orange- to orange-red-pigmented colonies on BHI agar and Columbia agar supplemented with $5 \%$ sheep blood. Cells were Grampositive rods and were non-acid-alcohol-fast. The organism was able to grow at 22 and $30{ }^{\circ} \mathrm{C}$ but not at higher temperatures. It is evident from Table 1 that strain IMMIB $\mathrm{SR}-4^{\mathrm{T}}$ can be readily differentiated from the type strains of the four recognized Williamsia species. It is of particular note that only isolate IMMIB SR $-4^{\mathrm{T}}$ was able to hydrolyse gelatin and to utilize acetamide and serine as simultaneous nitrogen and carbon sources for energy. The biochemical properties of strain IMMIB SR $-4^{\mathrm{T}}$ are given in the species description below. It is apparent from the genotypic and phenotypic data presented that strain IMMIB SR $-4^{\mathrm{T}}$ represents a novel species of the genus Williamsia, for which the name Williamsia serinedens sp. nov. is proposed.

\section{Description of Williamsia serinedens sp. nov.}

Williamsia serinedens (se.ri.ne'dens. N.L. n. serinum serine; L. part. pres. edens eating; N.L. part. adj. serinedens eating serine).

Forms smooth, orange- to orange-red-pigmented colonies on agar media. Cells are Gram-positive rods and are
Table 1. Differential physiological characteristics between strain IMMIB SR-4 ${ }^{\top}$ and type strains of Williamsia species

Strains: strain IMMIB SR $-4^{\mathrm{T}} ; 2, W$. deligens DSM $44902^{\mathrm{T}} ; 3, W$. marianensis DSM $44944^{\mathrm{T}}$; 4, W. maris DSM 44693 ${ }^{\mathrm{T}}$; 5 , W. muralis DSM $44343^{\mathrm{T}}$. Data were obtained in this study. All strains were positive for utilization of acetate, citrate, glucose, mannitol, paraffin and urea and negative for utilization of adipic acid, cellobiose, isoamyl alcohol, lactose, melezitose, ornithine, proline and raffinose and hydrolysis of adenine, casein, elastin, aesculin, guanine, hypoxanthine, tyrosine and xanthine. -, Negative; +, positive; $\mathrm{w}$, utilized weakly after 3 weeks incubation.

\begin{tabular}{|lccccc|}
\hline Characteristic & $\mathbf{1}$ & $\mathbf{2}$ & $\mathbf{3}$ & $\mathbf{4}$ & $\mathbf{5}$ \\
\hline Hydrolysis of: & & & & & \\
$\quad$ Gelatin & + & - & - & - & - \\
Testosterone & - & - & + & - & + \\
Utilization as sole sources & & & & & \\
of carbon and energy: & & & & & \\
Adonitol & + & - & + & - & + \\
L-Arabinose & + & - & + & - & + \\
2,3-Butandiol & + & + & + & - & + \\
meso-Erythritol & + & - & + & - & + \\
Galactose & + & - & - & + & - \\
Gluconate & - & - & + & - & + \\
Lactate & + & - & - & + & + \\
myo-Inositol & - & - & - & + & - \\
Maltose & + & + & - & + & - \\
Rhamnose & - & - & + & - & + \\
D-Sorbitol & + & + & + & - & + \\
Sucrose & + & + & + & - & + \\
Trehalose & + & + & + & - & + \\
1,2-Propandiol & + & - & - & + & + \\
$m$-Hydroxybenzoate & - & - & - & - & + \\
p-Hydroxybenzoate & + & - & - & + & + \\
D-Xylose & + & + & + & - & + \\
Utilization as sole sources & & & & & \\
of carbon and nitrogen: & & & & & \\
Acetamide & + & w & - & - & - \\
L-Alanine & + & + & + & - & + \\
Serine & + & - & - & - & - \\
& & & & & \\
\hline
\end{tabular}

non-acid-alcohol-fast. Grows at $22-30{ }^{\circ} \mathrm{C}$, but not at higher temperatures. Contains the salient chemotaxonomic characteristics of the genus Williamsia. Its mycolic acids were cleaved on pyrolysis to release $\mathrm{C}_{16: 0}$ and $\mathrm{C}_{18: 0}$ fatty acids as the major products. The fatty acid profile consists mainly of straight-chain saturated, unsaturated and 10-methylbranched fatty acids. Hydrolyses gelatin and urea but not adenine, casein, elastin, aesculin, guanine, hypoxanthine, testosterone, tyrosine or xanthine. Assimilates acetate, adonitol, L-arabinose, 2,3-butandiol, citrate, meso-erythritol, galactose, glucose, $p$-hydroxybenzoate, lactate, maltose, mannitol, paraffin, 1,2-propandiol, sucrose, sorbitol, trehalose and xylose as carbon sources, but not adipate, isoamyl alcohol, cellobiose, gluconate, $m$-hydroxybenzoate, myo-inositol, lactose, melezitose, raffinose or rhamnose. 
Utilizes acetamide, L-alanine and serine as simultaneous carbon and nitrogen sources, but not arginine, gelatin, ornithine or proline.

The type strain, IMMIB SR $-4^{\mathrm{T}}\left(=\mathrm{DSM} 45037^{\mathrm{T}}=\mathrm{CCUG}\right.$ $53151^{\mathrm{T}}$ ), was isolated from an oil-contaminated soil sample in Chyai County, Taiwan.

\section{Acknowledgements}

This research was partially supported by a grant from the Ministry of Economic Affairs and National Science Council, Taiwan, ROC. We thank Professor Dr Hans-Georg Trüper for nomenclatural advice and W. S. Huang for technical assistance.

\section{References}

Becker, B., Lechevalier, M. P., Gordon, R. E. \& Lechevalier, H. A. (1964). Rapid differentiation between Nocardia and Streptomyces by paper chromatography of whole cell hydrolysates. Appl Microbiol 12, 421-423.

Brosius, J., Palmer, M. L., Kennedy, P. J. \& Noller, H. F. (1978). Complete nucleotide sequence of a $16 \mathrm{~S}$ ribosomal RNA gene from Escherichia coli. Proc Natl Acad Sci U S A 75, 4801-4805.

Collins, M. D., Pirouz, T., Goodfellow, M. \& Minnikin, D. E. (1977). Distribution of menaquinones in actinomycetes and corynebacteria. J Gen Microbiol 100, 221-230.

Felsenstein, J. (1981). Evolutionary trees from DNA sequences: a maximum likelihood approach. J Mol Evol 17, 368-376.

Felsenstein, J. (1985). Confidence limits on phylogenies: an approach using the bootstrap. Evolution 39, 783-791.

Gordon, R. E. (1966). Some criteria for the recognition of Nocardia madurae (Vincent) Blanchard. J Gen Microbiol 45, 355-364.

Gordon, R. E. (1967). The taxonomy of soil bacteria. In The Ecology of Soil Bacteria, pp. 293-321. Edited by T. R. G. Gray \& B. Parkinson. Liverpool: Liverpool University Press.

Gordon, R. E. \& Mihm, J. M. (1957). A comparative study of some strains received as nocardiae. J Bacteriol 73, 15-27.

Jukes, T. H. \& Cantor, C. R. (1969). Evolution of protein molecules. In Mammalian Protein Metabolism, pp. 21-132. Edited by H. N. Munro. New York: Academic Press.

Kämpfer, P., Anderson, M. A., Rainey, F. A., Kroppenstedt, R. M. \& Salkinoja-Salonen, M. (1999). Williamsia muralis gen. nov., sp. nov., isolated from the indoor environment of a children's day care centre. Int J Syst Bacteriol 49, 681-687.

Kluge, A. G. \& Farris, F. S. (1969). Quantitative phyletics and the evolution of anurans. Syst Zool 18, 1-32.

Lechevalier, M. P. (1968). Identification of aerobic actinomycetes of clinical importance. J Lab Clin Med 71, 934-944.

Lechevalier, M. P. \& Lechevalier, H. A. (1970). Chemical composition as a criterion in the classification of aerobic actinomycetes. Int J Syst Bacteriol 20, 435-443.
Lechevalier, M. P., De Bièvre, C. \& Lechevalier, H. A. (1977). Chemotaxonomy of aerobic actinomycetes: phospholipid composition. Biochem Syst Ecol 5, 249-260.

Ludwig, W., Strunk, O., Westram, R., Richter, L., Meier, H., Yadhukumar, Buchner, A., Lai, T., Steppi, S. \& other authors (2004). ARB: a software environment for sequence data. Nucleic Acids Res 32, 1363-1371.

Minnikin, D. E., Hutchinson, I. G., Caldicott, A. B. \& Goodfellow, M. (1980). Thin-layer chromatography of methanolysates of mycolic acid-containing bacteria. J Chromatogr 188, 221-223.

Pathom-Aree, W., Nogi, Y., Sutcliffe, I. C., Ward, A. C., Horikoshi, K., Bull, A. T. \& Goodfellow, M. (2006). Williamsia marianensis sp. nov., a novel actinomycete isolated from the Mariana Trench. Int J Syst Evol Microbiol 56, 1123-1126.

Rainey, F. A., Ward-Rainey, N., Kroppenstedt, R. M. \& Stackebrandt, E. (1996). The genus Nocardiopsis represents a phylogenetically coherent taxon and a distinct actinomycete lineage: proposal of Nocardiopsiaceae fam. nov. Int J Syst Bacteriol 46, 1088-1092.

Saitou, N. \& Nei, M. (1987). The neighbor-joining method: a new method for reconstructing phylogenetic trees. Mol Biol Evol 4, 406-425.

Stach, J. E. M., Maldonado, L. A., Ward, A. C., Bull, A. T. \& Goodfellow, M. (2004). Williamsia maris sp. nov., a novel actinomycete isolated from the Sea of Japan. Int J Syst Evol Microbiol 54, 191-194.

Stackebrandt, E. \& Goebel, B. M. (1994). Taxonomic note: a place of DNA-DNA reassociation and $16 \mathrm{~S}$ rRNA sequence analysis in the present species definition in bacteriology. Int J Syst Bacteriol 44, 846-849.

Stackebrandt, E., Rainey, F. A. \& Ward-Rainey, N. L. (1997). Proposal for a new hierarchic classification system, Actinobacteria classis nov. Int J Syst Bacteriol 47, 479-491.

Yassin, A. F. (1988). Chemotaxonomische Untersuchungen zur vereinfachten Differenzierung und Identifizierung von aeroben Aktinomyzeten und Mykobakterien. Inaugural-Dissertation zur Erlangung des Doktorgrades der Mathematische-Naturwissenschaftlichen Fakultät der Rheinischen Friedrich-Wilhelms-Universität Bonn (in German).

Yassin, A. F. \& Hupfer, H. (2006). Williamsia deligens sp. nov., isolated from human blood. Int J Syst Evol Microbiol 56, 193-197.

Yassin, A. F., Binder, C. \& Schaal, K. P. (1993a). Identification of mycobacterial isolates by thin-layer and capillary gas-liquid chromatography under diagnostic routine conditions. Zentralbl Bakteriol 278, 34-48.

Yassin, A. F., Haggenei, B., Budzikiewicz, H. \& Schaal, K. P. (1993b). Fatty acid and polar lipid composition of the genus Amycolatopsis: application of fast atom bombardment mass spectrometry to structure analysis of underivatized phospholipids. Int J Syst Bacteriol 43, 414-420.

Yassin, A. F., Rainey, F. A., Brzezinka, H., Burghardt, J., Lee, H. L. \& Schaal, K. P. (1995). Tsukamurella inchonensis sp. nov. Int J Syst Bacteriol 45, 522-527. 